https://helda.helsinki.fi

Dealing with plagiarism in the academic community : emotional engagement and moral distress

\title{
Vehviläinen, Sanna
}

2018-01

Vehviläinen , S , Löfström , E \& Nevgi , A 2018 , ' Dealing with plagiarism in the academic community : emotional engagement and moral distress ' , Higher Education , vol. 75 , no. 1 , pp. 1-18 . https://doi.org/10.1007/s10734-017-0112-6

http://hdl.handle.net/10138/309456

https://doi.org/10.1007/s10734-017-0112-6

unspecified

publishedVersion

Downloaded from Helda, University of Helsinki institutional repository.

This is an electronic reprint of the original article.

This reprint may differ from the original in pagination and typographic detail.

Please cite the original version. 


\title{
Dealing with plagiarism in the academic community: emotional engagement and moral distress
}

\author{
Sanna Vehviläinen ${ }^{1} \cdot$ Erika Löfström $^{2} \cdot$ Anne Nevgi $^{2}$
}

Published online: 6 February 2017

(C) Springer Science+Business Media Dordrecht 2017

\begin{abstract}
This article deals with the demands that plagiarism places on academic communities, and with the resources staff possess in dealing with these demands. It is suggested that plagiarism ought to be placed in the context of network of intertwining communities (scholarly, pedagogical and administrative), to which participants are engaged to a different extent. The relationship to the ethical issue of plagiarism is related to the subject's engagement in these communities. The article examines the way teachers deal with plagiarism from the point of view of work engagement and work-related wellbeing. In particular, we analyse job demands created by episodes of dealing with plagiarism as well as job resources teachers possess that aid them in coping with these demands. We used thematic analysis of semistructured interviews of teachers in two universities. Our results show that the demands fall on five thematic categories: 1. rupture in the personal pedagogical relationship, 2. challenge on the supervisory "gatekeeping" responsibility; 3. a breach of the "everyday normality"; 4. ambivalence in explaining plagiarism and 5. the strain of performing the act of accusation. A key job demand in dealing with plagiarism is that teachers must balance both rule-ethical and care-ethical orientations in their reactions and actions. The resources teachers draw upon when dealing with these demands are: 1) dialogue and reflection in collegial dialogue 2) support from superiors and administration 3) shared protocols, procedures and plagiarism detection software. Our analysis shows that there are various demands that make dealing with plagiarism a strenuous task, but university environments also provide teachers with resources to cope with them.
\end{abstract}

Keywords Student plagiarism $\cdot$ university teachers $\cdot$ work engagement $\cdot$ job demands $\cdot$ job resources $\cdot$ Academic integrity

Sanna Vehviläinen

sanna.vehvilainen@uef.fi

1 University of Eastern Finland, PO Box 111, 80101 Joensuu, Finland

2 Centre for University Teaching and Learning, University of Helsinki, 00014 Helsinki, Finland 


\section{Introduction: Plagiarism as a problem for academia}

Plagiarism has been characterised as a "Pandora's box": opening it will bring up something too frightening to look at and will likely cause havoc and chaos (Sutherland-Smith 2005). Indeed, student plagiarism seems to arouse conflicting emotions and emotional reactions among academics (Nevgi and Löfström 2014). In this article we examine how university teachers deal with student plagiarism from the viewpoint of work engagement and work-related wellbeing. We show how teachers narrate the strain of student plagiarism for teaching faculty and discuss their experiences for dealing with it. We analyse what makes plagiarism a stressful situation for teaching faculty and discuss their experiences with the resources available for dealing with it.

Scholars differ in their definitions of plagiarism (e.g. Barrett and Cox 2005; Gullifer and Tyson 2014; Macdonald and Carroll 2006). Academic communities also have various approaches to student plagiarism as a moral problem (Valentine 2006; East 2010). The rule ethical approach is based on the notion of the universal application of a rule viewed as detached from the subject. The care ethical approach places the act in relation to the actor's intentions and understandings. The care ethical approach is based on the idea of virtues as guiding principles and of nurturing the students' growth in these virtues. The outcome of alleged plagiarism, then, depends on what kind of transgression plagiarism is defined to be. If seen as a matter of competence or convention, the remedy likely to be proposed is education. If plagiarism is regarded as a moral problem and a matter of choice, which is the case in some university documents and policy statements, then it is likely to lead to an emphasis on "catching cheats".

In research, the volitional aspect of plagiarism is also emphasised: it is a matter of moral choice. However, definitions and boundaries of plagiarism in academia are intertwined with notions of competence and expertise, which vary culturally (Street 2004; Sutherland-Smith 2005; East 2010). The issue of what counts as plagiarism is connected with issues of scholarly authorship as well as with the degree of autonomy a student is expected to master in a particular phase of study, whether at the master's or the PhD level (Sutherland-Smith 2005). There are no universal answers to these questions.

Research on plagiarism has identified a shift from reactive measures to more proactive approaches in facilitating academic integrity. From catching and disciplining cheats the current trend appears to be towards teaching responsible conduct in research (Ferguson et al. 2007). A proactive approach, however, requires discussion in the scholarly community about what academic integrity is and whose responsibility it is (Collins and Amodeo 2005; Gullifer and Tyson 2010; East and Donnelly 2012; Löfström et al. 2015). In this article we approach academics' experiences with student plagiarism from the perspective of the demands caused by such plagiarism, and we examine the resources available for coping with these situations. As theoretical background, we first examine plagiarism as academic dishonesty and the way academics deal with the practice. We will approach academics' distress caused by student plagiarism from the perspective of job demands and resources.

\section{Plagiarism as a form of academic dishonesty}

The most common definition of plagiarism is to describe it as literary and intellectual theft, stealing by copying the text or ideas of someone else and presenting these as one's own 
without crediting the original author (Park 2003). The etymology of the word plagiarism has been traced to the Latin noun plagarius (meaning kidnapper, seducer, plunderer, literary thief), derived from plagium (kidnapping) and from plaga (snare, net) (Barnhart 1988, 801, according to Park 2003). Plagiarism thus means an act of dishonesty related to authorship and copyright, a wrong against the original author by stealing the idea and/or the text and presenting it as one's own (Walker 2010; Ercegovac and Richardson 2004, 302). Furthermore, plagiarism is seen both as an abuse of another's intellectual production and as giving a false statement concerning one's own contribution as primary without acknowledging the original creator. These two aspects of plagiarism - intellectual theft and cheating - are based on different frameworks.

Plagiarism is an illegal act or an abuse of all kinds of intellectual products and artefacts of culture, science, journalism, literature, music, theatre, films (cf. Park 2003). Copyright and ownership of intellectual property in terms of being an owner of one's own text and the ideas expressed therein is a central ethical principle in Western cultural history. This idea of autonomy of copyright and ownership of one's own text has not always been self-evident. There have been times in history when copying someone else's text has been considered as the highest form of flattery, and not a vice as it is today (Park 2003). The Licensing of the Press Act 1662 and the Statute of Anne 1709 (also known as the Copyright Act 1709) have been considered as having established copyright as the legal ownership of intellectual property such as books and other texts (Deazley 2008). Plagiarism is also a form of educational dishonesty, that is, cheating, which can take place in all forms of formal education (Sisti 2007). Education and higher-level degrees are not only forms of learning, but also means of securing positions in society.

\section{Dealing with student plagiarism in academia}

Student plagiarism is considered an unethical practice and not acceptable in academia. Such plagiarism is part of the larger phenomenon of academic dishonesty and strongly contrasts with academic integrity and ethical rules of research. Since the development of the internet and the spread of information and communication technology, student plagiarism has become an ever-expanding issue in higher education (Comas-Forgas and Sureda-Negre 2010). Students recognise in general what crude plagiarism is, but may not be able to distinguish the finer aspects of proper referencing and paraphrasing (e.g. Roig 1999; Gullifer and Tyson 2010). Students are expected to develop their skills in academic writing during their degree studies, and they are not to cheat on exams or other assignments. However, students are sometimes confused about what constitutes plagiarism and about how other forms of academic misconduct, such as cheating or collusion, differ from plagiarism (Ashworth et al. 1997; Gullifer and Tyson 2010, 2014).

Different explanations have been offered for why students plagiarise. Research on individual characteristics and personal factors has presented diverse views of who is likely to plagiarise (cf. Walker 2010; Comas-Forgas and Sureda-Negre 2010) and to what extent conceptions of plagiarism are culturally determined (Wheeler 2009; Gilmore et al. 2010). Research on student plagiarism has focused on how students conceptualise plagiarism, how much they engage in misconduct such as plagiarism, on what moral grounds they debate and justify dubious actions (Granitz and Loewy 2006) and how big a problem students consider plagiarism to be (Arhin 2009; Walker 2010; Löfström and Kupila 2013). Researchers have 
suggested that the internet and technology make it easier to plagiarise and have pointed out that people tend to be more lenient in the use of internet sources (Guyette et al. 2008; Arhin 2009; Comas-Forgas and Sureda-Negre 2010; Ison 2012). Yet current scholarship is demanding that something must be done about plagiarism. Text-matching software (e.g. Walker 2010) and honour codes (e.g. Turner and Beemsterboer 2003) have been suggested as solutions to problems of integrity and plagiarism. Text-matching software, however, does not replace pedagogical approaches for teaching students academic writing, values and appropriate study and citation strategies (Löfström and Kupila 2013).

\section{Plagiarism as a job demand for academic staff}

Based on the community and literacy perspective, we propose that plagiarism should be viewed as intertwined with the ways in which different parties (students, teachers, researchers, academic leaders, administrators) are engaged with the academic community and their various interests (Flint et al. 2006; Sutherland-Smith 2005, 90). Plagiarism is connected to three intertwining, although analytically separate, activity systems (Engeström 1999): research, pedagogy and administration. For instance, a master's thesis constitutes a piece of research, creating new knowledge, but also a learning task, developing academic skills. This results in a study attainment and a credit, administered and recorded by the study administration. The consequences of plagiarism are constituted differently in these activity systems and their participants will have different professional and ethical standpoints for approaching plagiarism. In our analysis, we are interested in how university teachers experience plagiarism.

The academic community should be able to speak openly about what sort of conduct is acceptable in terms of fair pedagogy, equal treatment of all students and acceptable research conduct (Collins and Amodeo 2005; East and Donnelly 2012). Recently, researchers have argued that academic communities should find ways to reshape the individualistic teaching culture into a more shared pedagogical culture and active community building (e.g. Dysthe et al. 2006; Pyhältö et al. 2009: Vehviläinen and Löfström 2016; Mårtenson 2014). Successful prevention of plagiarism requires that the academic community has a systematic and assertive way of addressing academic integrity and plagiarism, both on proactive and reactive terms.

\section{Moral dilemmas and work engagement}

Our interest in plagiarism as an issue of well-being in the academic community initially stems from our longstanding activities in pedagogical staff development in two universities. There we have often encountered academic teachers' emotional reactions and expressions of personal concern towards plagiarising. As we turned to research literature, we found that confrontation with students' overt academic misconduct has been shown to be stressful (Coren 2012), burdensome and painful (Fontana 2009) for university teachers. Dealing with plagiarism, in particular, is suggested to be stressful for academic staff (Sutherland-Smith 2005; Collins and Amodeo 2005). Various factors cause it to be a demanding task. First of all, it has a nature of a taboo subject: Teachers may be reluctant to report cases of student plagiarism, since they worry about exposing their own practice and someone finding fault in it. Second, exposing suspected plagiarism may also lead to conflict in the pedagogical community or with students (Sutherland-Smith 2005; Fontana 2009). Third, academics may be reluctant to expose a student suspected of plagiarism to official procedures as recommended by official disciplinary 
guidelines if they perceive that these policies are not sufficiently sensitive to take care for the student's possibilities to continue studies (de Jager and Brown 2010). Finally, it is an arduous task to make a case and prove student plagiarism (Sutherland-Smith 2005; Larkham and Manns 2002) or cheating (Busch and Bilgin 2014). Research in nursing sciences has shown that moral dilemmas are a central source of work-related stress (for instance, Kälvemark et al. 2004; Hamric 2000). Also, pupil misbehaviour has been shown to be a central source of job demand for school teachers (Hakanen et al. 2006). While we recognise that the studies referred to above have not specifically focused on university teacher stress or emotional burden experienced in relation to student plagiarism, we identify that there are "weak signals" (i.e. observations or developments that are still ambiguous) in literature suggesting that also university teachers are affected by such experiences. One of our aims has been to explore whether these weak signals are on to something relevant; a phenomenon that might bear consequences for how university teachers experience job demands and resources.

In the study of well-being at work, there has been a considerable shift from focusing on demanding elements to analysing the interplay between job demands and job resources (Hakanen et al. 2006, 2008; Bakker and Demerouti 2007). The Job Resources-Demands model suggests that occupations have a set of features that present psychological or physiological demands (which require sustained cognitive or emotional effort and skills and therefore exact certain costs from the individual), as well as resources (features that are functional, restorative or that stimulate learning and development). Job demands and resources can be identified on physiological, psychological, social or organizational levels. Studies have also suggested that job resources can act as buffers against more serious costs of the demands (such as burnout). Furthermore, job resources are not only important as a means of controlling demands, but also are valued in their own right and have motivational force (Bakker and Demerouti 2007).

\section{Research questions}

In this study we analyse both the job demands of plagiarism on teachers and the resources teachers have for dealing with these demands. Our research questions are:

1. How do academic teachers describe the demanding elements of student plagiarism?

2. What resources serve an enabling, restorative function for academics who have dealt with student plagiarism?

\section{Data and methods}

Our aim is to present a qualitative analysis on the nature of student plagiarism as a job demand on teachers. We were interested in teachers' experiences of student plagiarism, and thus, wanted to recruit teachers who had experiences of it, i.e. according to their own interpretation plagiarism had taken place. In some cases plagiarism had been "verified" by others, in other cases, if the teacher had not pursued the matter further, the interpretation of plagiarism remained the individual teacher's interpretation. Nevertheless, the experience of plagiarism remained. We had a wealth of anecdotal evidence from discussions with academic teachers and administrators involved in staff development, that teachers find student plagiarism burdensome and difficult to deal with. Recognising that no two narrations were alike we decided to collect 
data through qualitative semi-structured interview. This way we could keep the interviews focused while allowing the distinct features of every story to be expressed.

Our corpus contains interviews from two universities, and two different institutional arrangements with respect to student plagiarism. Our intention is not to provide a comparative analysis between two universities, but to highlight the nature of the strenuous experience as it is depicted in the teachers' discourse, and show what job resources are relevant for teachers. By collecting data in two institutions we attempted to overcome the problem of single-institution research where the results may be more a consequence of the institutional context rather than describing the phenomenon itself. The fact that we were able to apply the same analytical framework in both contexts suggests that the nature of demands on teachers induced by student plagiarism exists as a phenomenon beyond institutional boarders.

The first data set, from university A, was collected between 2011 and 2015 and consists of 11 interviews of university teachers collected by the second and third authors of our study. The interviewees were academics who had been participating in pedagogical development courses of assessment student learning, and reported that they had encountered student plagiarism. The second data set was collected by the first author from university B in 2014. It consists of seven interviews with teachers who had been involved in hearings to review potential cases of student plagiarism. The context for plagiarism was mostly thesis writing, but also other study assignments. We used an interview protocol from a prior study in university A (Nevgi and Löfström, 2014) with slight modifications for university B. These modifications included added questions on the (at the time) recently launched plagiarism detection software and related procedures.

All teachers gave their consent for the research use of the interview material. The data have been made anonymous by means of excluding information that would give away identities of persons, units or faculties. For the sake of anonymity, we have adopted the principle of using the feminine pronoun for all teachers and the masculine pronoun for all students.

Our analysis was theory driven in the sense that we sought both job demand and job resource elements to identify stressful, contradictory, distressing or otherwise demanding features as well as any features that teachers described as supportive, helpful, comforting or otherwise useful. We applied thematic content analysis and we focussed on specific thematic themes in the rounds of analyses (cf. Braun Clarke and 2006; Vaismoradi et al. 2013).

The first round of analyses was conducted on each corpus by those who collected it. We carried out the analysis under separate thematic rounds, systematically addressing:

- Emotional reactions to plagiarism. Emotional reactions, prominent in both data, were the key to detect talk about demands. Emotional reactions were informative in terms of the nature of the pedagogical relationship that the teachers had assumed to share with the students. Emotional reactions also provided a key to the disbelief, estrangement and ambivalence as well as guilt, deep responsibility and commitment the teachers expressed. Emotion talk also revealed orientations to two distinct ethical frameworks through which academics approach cases of plagiarism.

- Views of plagiarism as a transgression and whether it is deliberate or accidental. These accounts provided for the conceptual understandings regarding student plagiarism, the conflicting explanations teachers provided and the way in which they were left in conflict about whether plagiarism is a matter of competence or morality. Discussions of the nature of plagiarism also showed that for teachers, catching plagiarism is a matter of professional 
pride, while they also are concerned of the restorative aspects of their conduct and the possibility for the student to make amends and return to the studies.

- Additional rounds on any separate demand elements. These, in combination with the emotion analyses, provided keys to the strain of having to make the case for plagiarism while not being able to discuss it openly in the community.

- Resource elements - with these readings emerged the types of resources teachers considered relevant. These resources were often discussed in connection to the emotional talk.

The separate rounds ensured a systematic and thorough reading of the material. These separate analyses produced a set of subcategories, which were identified in both data sets. We then were able to identify mediating themes, connecting the subcategories. We will use these mediating themes to introduce the results. Together these mediating themes accounted for what makes plagiarism difficult and burdensome for teachers, and they also revealed key supportive elements. We cross-validated our analyses by analysing a sample of one another's data using the existing categories. We paid attention to agreement both in coding and to whether the existing set of categories covered the points raised in the data.

\section{Results: Job demands created by plagiarism}

The mediating themes regarding job demands were:

1. Rupture in the personal pedagogical relationship

2. Challenge to the supervisory, gate-keeping responsibility

3. A breach in everyday normality

4. Ambivalence in the explanations of plagiarism

5. The burden of accusation, verifying and disciplining.

In this section we will discuss each theme using examples from the data. We have numbered our interviews and use codes $\mathrm{A}$ and $\mathrm{B}$ to refer to the respective corpuses.

\section{Rupture in the personal pedagogical relationship}

The first category of job demands in teachers' discourse has to do with the personal pedagogical relationship that the teachers assume to have shared with students. This commitment is a care ethical one: the teacher is committed to facilitating the student's learning process. When plagiarism brings the study process to a halt, it deprives the teacher of the pleasure of seeing the student accomplish something and show their expertise. Many teachers consider the gratification of a student's accomplishment and success the most rewarding part of supervision (Vehviläinen and Löfström 2016). Plagiarism not only hurts the pedagogical relationship by violating trust, it also deprives teachers of their major reward.

It is quite a shock when it comes out. ( ...) First you're all happy that the student has completed this, and then right away there is this (...) "falling". (B3)

All teachers brought up relatively strong, negative emotional reactions to student plagiarism. It is in the talk about emotional reactions that the issue of moral transgression turned out 
to be most accessible. Teachers reported reactions having to do with the personal relationship with the student: the teachers were disappointed, hurt or angry.

Hate, anger, annoyance and then disappointment, and especially at first it was this feeling of deep disappointment, and then a kind of feeling of uncertainty, as this was my first supervision of a master's thesis, and I thought that I've failed as a supervisor, that I've not been able to advise and supervise him in the right way (...) and finally it was all of the total disappointment and losing my trust in him, and at the end it was also a kind of sadness and being surprised at how this student had dared to do so [to plagiarise] so many times and always he was exposed, always he was caught [plagiarising]. (A1)

In these reactions the assumed trust is broken and the teacher feels hurt and disillusioned. It may feel like the picture of the student is altogether altered. These reactions reveal the nature of the commitment the teacher has made to the student and an expectation that this commitment is mutual and sincere. Many teachers described chain reactions whereby their emotions alternated, portraying the ruptured relationship, care-ethical empathy and sadness for the student.

Some emotional reactions that place the parties in a personal relationship are more focused on the student's experience. The empathic reactions display prominent care-ethical reasoning: there is compassion for the student's situation, which is viewed as a tragedy. This tragedy is portrayed as mostly harmful to the student rather than hurting the teacher or the pedagogical relationship.

And it was exactly that he had this horrendous shame. Then awful anxiety, and then he was beside himself. I don't know if he had any debriefing anywhere before, I mean at the point when the notification came (...) I would have hoped that he could have gotten it for himself. (...) I was in such sorrow because I thought like, 'couldn't we somehow', I mean, must it go like this? (B6)

Many teachers also emphasised that how the student behaved makes a difference: whether he seemed genuinely to regret the deed or was without remorse. A student who appeared calculating or cynical seemed to hurt teachers the most, since the breach of reciprocity is then the greatest.

But they have been very different as experiences; I mean, the first student was clearly sorry and understood that he had done wrong (...) and admitted that, yes, he had done this and just hadn't been thinking, so that it was perhaps sort of thoughtlessness (...) But this other one is, it is more difficult in the sense that he doesn't (...). And because it was this sort of repeated case. (...) I mean, it is sort of like a different sort of strain when it just doesn't fit the teacher's sense of right and wrong; like, why does the student do this and doesn't admit, even with the clearest evidence, that he has done this? So in that sense, it is mentally more stressful for the teacher compared to this first student who regretted and admitted his mistake. (B2)

\section{A challenge to the supervisory, gate-keeping responsibility}

There are also strong emotional reactions that are less engaged with the personal pedagogical relationship. Instead, they place the teacher in the position of senior responsibility. These 
reactions stem more from the rule ethical orientation, and they differ in terms of intensity and in terms of the kind of responsibility the teacher assumes. This responsibility is one of a gatekeeping nature: it is the task of the teacher or the teacher collective to notice, spot and eliminate plagiarism before students proceed to their work-life careers.

Firstly, there are numerous narrations of guilt. Guilt may arise from not having spotted the plagiarism earlier or from the concern over whether one has properly instructed the students on ethical conduct. The underlying question in these reactions was: was it somehow my fault?

I guess (...) guilt would be the strongest emotion. I mean first I thought (...) as I have supervised, anyway, or whatever my role was, but I do remember when (...) the email came to me (...). I felt it sort of physically (...), like somehow I felt a bit shaky and sort of like, 'oh my god', and my pulse went up and sort of like, 'now what'. Then I went straight to see this, whether this other supervisor was around (...), so maybe these physical sensations were quite strong so that during that day I couldn't really do much else. (B3)

Some teachers discussed guilt as a potential reaction that more junior teachers might have or they narrated their colleagues' experiences. The category of guilt ties in with the shared conviction that plagiarism belongs to the realm of academic literacy, not only to the realm of moral choice and personal moral quality. Therefore, a case of plagiarism tends to raise the question of whether the students have been adequately instructed. The academic community always deals with a degree of shared responsibility, even shared authorship between the supervisor and the supervisee (Löfström and Pyhältö 2012, 2014). Thus, the issue of guilt will surface, no matter how convinced the staff may be that their teaching of academic integrity has been sufficient. The underlying issue of teachers' potential guilt also appears in narratives in which colleagues or superiors maintained that plagiarism is not the fault of the teachers.

Besides guilt, a supervisor may experience shame in cases of student plagiarism that are related to joint publications for a doctoral dissertation. For a supervisor it is a shock to learn that a doctoral student has plagiarised in their co-authored research papers and articles.

... sort of, on the one hand, I felt something like guilt, and on the other hand, like being betrayed, like how could he do this to me, to humiliate me in front of [my] international colleagues because we had to revise the article [when the plagiarism had been exposed], and then I had this fear that whether the other articles I've co-authored with him are also similar bombs, and so I had various feelings, and yes, there were feelings of anger at some moments.... (A10)

Feelings of shame are related to strong disappointment in oneself as a supervisor, feelings of failure as a supervisor and failing in the gate-keeping of academic standards.

The gate-keeping rule-ethical position also creates other reactions, from personal or collective relief (I/we gotcha!) to anger for having been fooled, and annoyance: it is just more tedious work for the teacher to be suspicious, checking manuscripts with Google or textmatching software.

Many teachers discussed their concern for the quality and reputation of the master's degree in connection with their emotional reactions, but also in their reflections over why plagiarism is wrong. One aspect of their gate-keeping role is to ensure that plagiarising students cannot pass through the system. A sense of relief, even professional pride, was 
connected with cases in which plagiarism had been detected and professionally dealt with.

(B)ut (...) it is good that we catch these, that we don't let through our hands master's or bachelor's [students] who after a few years will turn out like this. (B2)

\section{A breach in everyday normality}

A third element in the demands created by plagiarism is a sense that the world is suddenly "out of order". The component of disbelief, even shock and outrage, as the first reaction to the discovery of plagiarism is systematically apparent in the data. Plagiarism is clearly revealed to be something that disrupts the "benign order of everyday life" (Maynard 2003) - the assumed mutual sincerity of the pedagogical relationship.

(W)hen I opened the email the feeling was like, 'is this true'? (...) I mean, I was like taking it in, reading it again and thinking 'can this be true?' And maybe there was a sense of something unreal, like a surprise, or whatever it was, reading it. (B4)

The first reaction may vary in terms of its intensity. In any case everyone described some notion of surprise or disbelief. Plagiarism is not routine; it is disruptive news and seems to take teachers off-guard. When asked how the teachers viewed the phenomenon and what they had learned, many stated that the experience had been a "wake-up call" or an "eye-opener". They could no longer remain naïve about it. Such statements also imply there had been an illusion that was now shattered.

(Question: ...has this influenced your views about plagiarism?) (It) has influenced me in that I have been a bit naïve about it; I haven't understood (...) how obviously common a phenomenon it is, because if we think about how little we catch, these must be tips of the iceberg, these few cases we had. At least this is how I see it. (B2)

Some teachers expressed frustration and disappointment at the thought of having to act suspiciously in the future and view their students more cynically. Teachers may think it impossible to teach and supervise with a suspicious attitude.

This is the very reason why I wanted to discuss this issue with the student. Because I don't want, I mean I don't want to feel that I'm becoming more cynical and more non-trusting. I really don't want to be like that. So I wanted to discuss with the student because I wanted to understand the reasons why he ended up doing that, that deed. And somehow this helped me to understand him. Well, I really believe that I'm not capable of doing my job if I can't trust my students. (A3)

\section{Ambivalence in the explanations of plagiarism}

When explaining plagiarism and trying to interpret what it symptomises, teachers seem to share a certain ambivalence. They consider both intentional and unintentional plagiarism as real possibilities.

If I think about it then, like somehow, I think it can be unintentional. (...) I also think that if there is like that kind of example such as a table in the appendix, research put into a 
table, for example twenty studies, (describes a case where an entire literature review is copied) (...) But I do think that it can also be that [the students] don't mean to do it, although it turns out that way. (B4)

On the one hand, plagiarism surprised the teachers, but when they stopped to think about it, they saw that, to an extent, "it must have always been there". Some cases appeared to them clearly intentional and cynical. While admitting this, they felt that it would be frustrating and alienating to start suspecting everyone. This ambivalence is also evident when the teachers had to decide whether a student was sincerely sorry or not.

\section{The burden of accusation, verifying and disciplining}

The fifth category of demanding elements is connected with the strain of having to accuse the student. Accusing someone, or even bringing up a potential transgression, is emotionally strenuous. Any confrontational interaction is difficult, as it poses a threat to the social face of the other. Moreover, the accuser herself may feel guilty, for the reasons discussed in Sect. 6.2. Bringing up the suspected plagiarism may also cause the student to react in a hostile manner.

Besides the emotional strain, there is the further strain of finding evidence and proving the plagiarism. This often means planning new assignments to replace the plagiarised work, and it means extra work for the teacher.

(...) I put in several hours [to verify the plagiarism]; it took me probably a couple of days to do this then. But I wanted to be sure so that I wouldn't accuse the student of such a thing on weak grounds. (B8)

Not least, the act of accusing is strenuous because the risk of false accusation presents the frightening possibility of a libel.

Of course, there is also this side, this juridical side then, which might also scare teachers sometimes. (...) I mean, could it be considered like a libel or something... (B8)

The act of accusing is not always carried out alone. In our corpus B some teachers had experienced working collectively and joining a hearing in which a group of staff members handled the case with the student. Teachers may experience the workings of this "jury" in various ways. It may be difficult to try to talk in a neutral manner, so as not to say too much or to commit an assault.

(I)t was sort of like a strange situation somehow. (...) because it is, of course, it is sort of like an official situation (...) because everyone sort of takes care how to choose their words (...). I mean the whole situation felt so strange (...) I mean how do I choose my words so that I would make a clear point and (...) and that I don't say it so as to make him feel guilty, nothing like that, but just stating the point (...). I noticed that it is not at all an easy place for me to have to say things like that. (B4)

A teacher may also feel compassion for the student and a concern for the traumatizing effect of the accusation.

So if it is clumsy referencing, like, in my opinion unintentional and then kind of we don't teach it ourselves, then in my opinion, I don't know, if suddenly the student is charged with accusations of plagiarism, then I don't think it is pedagogically the best 
method, especially when the student then reacted by changing the subject. And it was also very traumatizing for me. [A6]

A final stressful element connected with suspected plagiarism is the silence around the topic. When the case is being examined, it is not considered appropriate to talk about it. One should not be treated as guilty until proven so. There also seems to be strong agreement that, while plagiarism should be banned, it is also important not to stigmatise the student. Therefore, the case is discussed only in the circle of those concerned. Teachers who are released from working on the case may be left out of the flow of information, and the case remains unresolved in their minds.

Of course, I've been keen to know, so I would have hoped that someone would contact me and tell me, because it's been really difficult for me to go up to someone and ask or to talk to other teachers about this. So I don't, I don't know how the process proceeded. I don't know what's been done and what conclusions have been drawn....

\section{Results: Job resources}

Teachers discussed various aspects of their work that helped them to manage the strains discussed above. The job resources were:

1. Conversations with colleagues and other reflective spaces

2. Support from superiors and administrative personnel

3. Shared playing rules, procedures and plagiarism-detection programmes

\section{Conversations with colleagues and reflective spaces}

The teachers in our data emphasised most of all the support from colleagues. It is essential to be able to discuss the plagiarism case with colleagues. Teachers shared the case with other teachers who were somehow involved (teachers who taught same assignments to other groups). They stated that such discussion was important emotionally and also because colleagues corroborated the accusation of plagiarism and eased the burden of responsibility in the act of accusing.

Uncertainty subsides when the onus for handling the case clearly shifted forward. I had been able to leave feedback, and we had a good and constructive discussion with the supervisor about the course of action. I clearly could have been stricter. In my opinion if students plagiarise, then the right to study should be terminated right away, and this is precisely [what is done] when there is verbatim plagiarism. But of course, sometimes you have to, if the student is otherwise talented and motivated, sometimes guide them. I believe that the person in charge of the course had a better, more informed view of this than I had, at least with regard to this particular group. (A11)

Some teachers felt that discussion with colleagues was enough of a "debriefing" for them, but they also pointed out that novice colleagues could perhaps need supervision or counselling 
to sort out their feelings. Some also admitted that they themselves could profit from supervisory reflective encounters.

It is clear that the teachers perceived plagiarism as a demanding situation requiring space for reflection. Some of them even expressed appreciation for the opportunity for reflection provided by the research interview. Some teachers pointed out that their own training included expertise in human relations, care and psychological issues, which were helpful in facing challenging situations in a pedagogical role.

Many teachers contended that it is important to have open discussions about plagiarism. Although individual cases must be dealt with cautiously, it would be important to have both university level and faculty level discussions about what plagiarism means to the communities, to acknowledge that it exists and to show that there are shared and systematic ways of dealing with it.

\section{Support from superiors and administrative personnel}

Teachers appreciated the administration's acknowledgement of their input in exposing plagiarism. Open and trustful relationships with their superiors helped the teachers discuss their suspicions of plagiarism, which shows that the teachers need their superiors to back them up and trust their expertise.

And then after that, I talked to my superior, and she gave me some advice and instructions and also where I could find more instructions on how teachers should act (...). Well, I got relatively free hands there, and I appreciated the opportunity to reflect on how to act. (A3)

The teachers also mentioned that it was important to have their superior explicitly assure them of their trust in the teacher's instruction of academic integrity as being appropriate and sufficient. Some also pointed out that the way in which members of the administrative staff handled the situations had a calming and compassionate air, comparable to professional supervision.

\section{Shared playing rules, procedures and plagiarism-detection programmes}

Most teachers pointed out that plagiarism-detection software is a turn for the good and a useful tool. Such software was relatively new to all our interviewees, as they were all interviewed either during a piloting phase or in the early stages of such software implementation. Along the same lines, university-level shared norms, protocols and playing rules were also considered useful.

But I myself feel that, at least now, after this experience, that this [software] implementation is all right, although many, many have been sort of asking like, what's the big deal (...). When we have these controlling measures then it surely lessens it [plagiarism], although one would hope that lessening plagiarism would mean that folks have learned good principles, but I mean surely this kind of measure will also prevent it. (B3)

Those teachers who had experience with the collective procedure of a "hearing", aided by the administrative staff, thought that it was beneficial and supportive. Many looked back on it as something they appreciated. 
At least, it was really beneficial that these two other colleagues (and I) were sort of very much in agreement and went through the case sort of amongst us who had been involved. Then we took on board our dean, and the study administration officer (...) was there too. And I thought it was good that the (...) the first contact with the student (...) was not just teachers, but also representatives from the administration (...); for this student it was particularly good, as he really wasn't about to admit to anything. (B10)

The teachers felt proud that plagiarism was exposed and handled with integrity at their university. Many of their explicit suggestions for development dealt with strengthening such shared procedures, so that everyone would know what to do, how to proceed and with whom to share the experience.

Several teachers also thought it was essential that they did not have to continue working with the student who had betrayed their trust. Thus, the case was managed by other members of the staff, and the renewed assignments were supervised and assessed by other teachers.

We have agreed on a principle that, when the trust is broken, then it is in the interest of the student, but also for the protection of the teacher that they don't need to continue it [=working together], so it means we always have to think like how, who [=continues with the student?]. (B2)

\section{Discussion}

The data sets in this study were not extensive, but they were gathered from two universities. As stated, the central themes emerged in both data sets; this suggests that we have identified relevant themes and expressed something that is shared in the academic cultures, despite the differences in practice in the chosen institutions. Plagiarism is experienced by the academics who encounter it as a demanding event - whether it is only suspected as in University A or also institutionally handled and evidenced as in University B. A collective procedure for handling suspected plagiarism had been established at University B. Naturally, this procedure was apparent in the teacher's discourse, while the teachers at University A did not have access to a collective protocol. However, they too emphasised the relevance of collegial support and opportunity for reflection and viewed these measures as restoring and empowering resources. While the data allowed us to identify the nature of the demands that teachers experience, they do not allow us to make reliable interpretations of the frequency or the prevalence of different demands. Instead, we have attempted to identify the variety of demands and to analyse why these demands are burdensome in the context of experiencing student plagiarism. While our data reached a "saturation point" in which the same themes began repeating themselves, it is possible that in another cultural context additional or other types of demands might emerge. We do not exclude the possibility of cultural influence on how plagiarism was experienced and how it was dealt with. However, to understand cultural differences, research would need to be expanded to include other types of higher education institutions (e.g. institutions of applied sciences) or institutions in other countries.

The chosen approach of the Job Resources-Demands Model (Hakanen et al. 2006; Bakker and Demerouti 2007) proved suitable for analysing the moral distress of teachers and interpreting their reactions and understandings in the context of the academic community and the intertwining systems of pedagogy and research. To our knowledge, the Job Resources- 
Demands Model has not been used in the context of university teacher experiences of student plagiarism. Thus, the study broadens the theoretical conceptualization of plagiarism as a source of emotional and moral distress, and also as a situation calling for collegiality and reflection.

Based on our analysis of the job demands, we suggest that in dealing with plagiarism (cf. also Valentine 2006; East 2010) teachers combine rule ethical and care ethical responsibility. Teachers are committed to students' learning, and with this commitment they are oriented to the moral activity and well-being of their students. However, they are also gatekeepers of the quality of their programmes (Löfström et al. 2015). Teachers are responsible for identifying and disciplining dishonesty. We suggest that this is a key job demand in teachers' entanglement with plagiarism: they need to attend to both rule-ethical and care-ethical orientations and personally balance both in their reflections, decision-making and actions.

Empathy, compassion and care-ethical reasoning are apparent not only in individual teachers' reactions, but also in narratives of how the pedagogical community, through its procedures, protects the student from stigma and provides a way back to study in the academic community. The collective practices for dealing cautiously with the suspected plagiarism aim at restoring the student's identity as a party in the pedagogical relationship. These practices also acknowledge the disillusionment of those teachers who have been personally hurt by the plagiarism. This is a way of redistributing the care-ethical and rule-ethical responsibilities in the collective so that a single teacher is not expected to stretch to all these roles.

Plagiarism breaches norms that are fundamental to teachers' own work as academics, but these expectations often remain un-explicated until broken. It may not be generally recognised just how much of themselves teachers invest in the pedagogical relationship. This dedication became obvious in analysing the teachers' reactions. Notably, for these teachers, the sense of academic integrity and sincerity tied together the activity systems of pedagogy and research. Viewing their students with suspicion would be highly alienating for them: it would suggest that students are not sincere members of the academic community. This all-encompassing sense of decency is something the teachers talked about in addressing how they viewed plagiarism as a transgression. It is a code of integrity that is taken to cover all aspects of academic work, and they expected this integrity to be a guiding idea as students' progress into their working lives.

For these reasons, these university teachers remained ambivalent in their explanations of plagiarism. If teachers were to treat plagiarism as a routine incident, then perhaps they would have more clear-cut and definite explanations about why plagiarism happens. Perhaps also their reactions would be more neutral. Our data then give a picture of Finnish university teachers trying to come to terms with something that is relatively unusual and disturbing. They are fighting cynicism and are not willing to accept the fact that students might not be generally treated as sincere members of the pedagogical community.

Yet another important dimension of the demands is the strain on both individuals and collectives caused by accusing someone of plagiarism. There is the emotional strain of blaming and confronting (cf. Coren 2012), and the strain of dealing with potential aspects of guilt and shared responsibility. There is also the extra work, and finally the need to act cautiously and not share information about the case to outsiders.

Although the demands weigh heavily in situations involving plagiarism, in the teachers' experiences there were also enabling resources. Teachers need support, and there are ways in which this support can be provided. Firstly, it is necessary to have general rules and practices for sharing the burdens of the demanding and complex teaching profession. Teachers are responsible for seeing that rules are followed and that the quality of the education and the 
degrees awarded are maintained. Simultaneously, teachers are juggling care-ethical considerations, which can conflict with demands to implement rules. Even if rules for handling alleged cases of plagiarism are in place, practices for balancing the various ethical demands are not always well developed.

Key resources are clearly a teacher's colleagues and the community. Pedagogical leadership is vital in dealing with alleged cases of plagiarism. Teachers must not be left to deal with the situation alone. Collegiality is created on the one hand through structures such as commonly shared rules and procedures, and on the other, through reflective, supportive collegial discussion (cf. also East and Donnelly 2012). The reflection can take many forms: between colleagues, in assigned teams or sometimes even in professional supervision or counselling. When a case of plagiarism emerges, the community needs to be ready to step in. It should be clear to all what to do. It is also important to ensure that the flow of information is uninterrupted and that the parties involved have access to sufficient information throughout. This will help teachers focus on solutions rather than leave them dangling in burdensome emotional reactions (e.g. Sutherland-Smith 2005) and will also enable them to achieve closure once the case is appropriately handled. At its best, successful collective management of a plagiarism case can be a source of professional pride for the staff.

When text-matching software is introduced, it provides an opportunity for the scholarly community to discuss academic integrity more broadly and create a shared understanding of these concepts and practices. The introduction of text-matching software created discussion in the two communities, but it appears that the opportunities for the academics to engage in a pro-active fashion had not been fully grasped. The use of text-matching software is in its early phases in both communities investigated in this study.

Furthermore, it is important to recognise the need for support for the less experienced teachers. University pedagogical training and mentoring could, to a greater extent, be harnessed in discussing the ethical aspects of university teachers' work and in finding ways in which to balance the sometimes contradictory demands. In this study we have investigated university teachers' experiences, but it would be equally important to understand how administrators and academic leaders deal with the issue of plagiarism, as well as to understand the students who have been accused of or caught plagiarising, together with those students whose work has been plagiarised.

Acknowledgements This work was supported by the Academy of Finland under Grant 252813 to the second author.

\section{References}

Arhin, A. O. (2009). A Pilot Study of Nursing Students' Perceptions of Academic Dishonesty: A Generation Y perspective. The ABNF Journal, 20(1), 17-21.

Ashworth, P., Bannister, P., Thorne, P., \& Students on the Qualitative Research Methods Course Unit. (1997). Guilty in whose eyes? University students' perceptions of cheating and plagiarism in academic work and assessment. Studies in Higher Education, 2(22), 187-203. doi:10.1080/03075079712331381034.

Bakker, A. B., \& Demerouti, E. (2007). The Job Demands-Resources model: state of the art. Journal of Managerial Psychology, 22(3), 309-328.

Barnhart, R. K. (Ed.) (1988). Chambers dictionary of etymology. Edinburgh: Chambers.

Barrett, R., \& Cox, A. L. (2005). 'At least they are learning something': the hazy line between collaboration and collusion. Assessment \& Evaluation in Higher Education, 30(2), 107-122. 
Braun, V., \& Clarke, V. (2006). Using thematic analysis in psychology. Qualitative Research in Psychology, 3(2), 77-101.

Busch, P., \& Bilgin, A. (2014). Student and staff understanding and reaction: academic integrity in an Australian university. Journal of Academic Ethics, 12, 227-243.

Collins, M. E., \& Amodeo, M. (2005). Responding to plagiarism in schools of social work: considerations and recommendations. Journal of Social Work Education, 41, 527-543.

Comas-Forgas, R., \& Sureda-Negre, J. (2010). Academic plagiarism: explanatory factors from students' perspective. Journal of Academic Ethics, 8, 217-232.

Coren, A. (2012). The theory of planned behavior: Will faculty confront students who cheat? Journal of Academic Ethics, 10, 171-184.

de Jager, K., \& Brown, C. (2010). The tangled web: investigating academics' views of plagiarism at the University of Cape Town. Studies in Higher Education, 5(35), 513-528. doi:10.1080/03075070903222641.

Deazley, R. (2008) Commentary on the Statute of Anne 1710, In L. Bently \& M. Kretschmer (eds.), Primary sources on copyright (1450-1900). Available at: www.copyrighthistory.org. Accessed 29 June 2015.

Dysthe, O., Samara, A., \& Westrheim, K. (2006). Multivoiced Supervision of Master's Students: A Case Study of Alternative Supervision Practices in Higher Education. Studies in Higher Education, 31(3), 299-318.

East, J. (2010). Judging plagiarism: a problem of morality and convention. Higher Education, 59, 69-83.

East, J., and Donnelly, L. (2012). Taking responsibility for academic integrity: A collaborative teaching and learning design. Journal of University Teaching \& Learning Practice, 9(3). http://ro.uow.edu.au/jutlp/vol9 /iss3/2. Accessed 20 June 2013.

Engeström, Y. (1999). Activity theory and individual and social transformation. In Y. Engeström, R. Miettinen, \& R. Punamäki (Eds.), Perspectives on Activity Theory. Cambridge: Cambridge University Press.

Ercegovac, Z., \& Richardson Jr., J. V. (2004). Academic Dishonesty, Plagiarism Included, in the Digital Age: A literature review. College \& Research Libraries, 65(4), 301-318.

Ferguson, K., Masur, S., Olson, L., Ramirez, J., Robyn, E., \& Schmaling, K. (2007). Enhancing the culture of research ethics on university campuses. Journal of Academic Ethics, 5, 189-198.

Flint, A., Clegg, S., \& Mcdonald, R. (2006). Exploring staff perceptions of student plagiarism. Journal of Further and Higher Education, 30(2), 145-156.

Fontana, J. S. (2009). Nursing faculty experiences of students' academic dishonesty. Journal of Nursing Education, 48(4), 181-185.

Gilmore, J., Strickland, D., Timmerman, B., Maher, M., \& Feldon, D. (2010). Weeds in the flower garden: An exploration of plagiarism in graduate students' research proposals and its connection to enculturation, ESL, and contextual factors. International Journal for Educational Integrity, 6(1), 13-28.

Granitz, N., \& Loewy, D. (2006). Applying Ethical Theories: Interpreting and Responding to Student Plagiarism. Journal of Business Ethics, 72, 293-306.

Gullifer, J., \& Tyson, G. A. (2010). Exploring university students' perceptions of plagiarism: A focus group study. Studies in Higher Education, 35(4), 463-481.

Gullifer, J., \& Tyson, G. A. (2014). Who has read the policy on plagiarism? Unpacking students' understanding of plagiarism. Studies in Higher Education, 7(39), 1202-1218. doi:10.1080/03075079.2013.777412.

Guyette Jr., R. W., King, C. G., \& Piotrowski, C. (2008). Business faculty views of online course cheating: evidence for a cohort effect. Organization Development Journal, 26(4), 25-31.

Hakanen, J., Bakker, A., \& Schaufeli, W. (2006). Burnout and work engagement among teachers. Journal of School Psychology, 43, 495-513.

Hakanen, J. J., Schaufeli, W. B., \& Ahola, K. (2008). The Job demands-resources model: A three-year crosslagged study of burnout, depression, commitment, and work engagement. Work \& Stress, 22(3), 224-241.

Hamric, A. B. (2000). Moral distress in everyday ethics. Nursing Outlook, 48, 199-201.

Ison, D. (2012). Plagiarism among dissertations: Prevalence at online institutions. Journal of Academic Ethics, $10(3), 227-236$.

Kälvemark, S., Höglund, A. T., Hansson, M. G., Westerholm, P., \& Arnetz, B. (2004). Living with conflictsethical dilemmas and moral stress in the health care system. Social Science and Medicine, 3(58), 1075-1084.

Larkham, P. J., \& Manns, S. (2002). Plagiarism and its treatment in Higher Education. Journal of Further and Higher Education, 26(4), 339-349. doi:10.1080/0309877022000021748.

Löfström, E., \& Kupila, P. (2013). The Instructional challenges of Student Plagiarism. Journal of Academic Ethics, 11, 231-242.

Löfström, E. and Pyhältö, K. (2012). The supervisory relationship as an arena for ethical problem-solving. Education Research International, article ID 961505, 1-12.

Löfström, E., \& Pyhältö, K. (2014). Ethical Issues in Doctoral Supervision - The perspectives of PhD students in the Natural and Behavioural Sciences. Ethics \& Behavior, 24(3), 195-214.

Löfström, E., Trotman, T., Furnari, M., \& Shephard, K. (2015). Who teaches academic integrity and how do they do it? Higher Education, 69(3), 435-448. 
Macdonald, R., \& Carroll, J. (2006). Plagiarism - a complex issue requiring a holistic institutional approach. Assessment \& Evaluation in Higher Education, 31(2), 233-245.

Mårtenson, K. (2014). Influencing teaching and learning microcultures. Academic development in a researchintensive university. $\mathrm{PhD}$ thesis, Lund University.

Maynard, D.W. (2003). Bad news, good news: Conversational order in everyday talk and clinical settings. Chicago: The University of Chicago Press.

Nevgi, A., \& Löfström, E. (2014). Discourses on student plagiarism among university teachers. A paper presented at the symposium "Discourse analysis as a method in researching university teachers and students" at EARLI SIG4 and SIG 17 Conference Assessing transitions in learning Leuven, 20-22.

Park, C. (2003). In (Other) People's Words: plagiarism by university students - literature and lessons. Assessment \& Evaluation in Higher Education, 28(5), 471-488.

Pyhältö, K., Stubb, J., \& Lonka, K. (2009). Developing a Scholarly Community as a Learning Environment for Ph.D. Students. International Journal for Academic Development, 14(3), 221-232.

Roig, M. (1999). When college students' attempts at paraphrasing become instances of potential plagiarism. Psychological Reports, 84, 973-982.

Sisti, D. A. (2007). How do High School Students Justify Internet Plagiarism? Ethics \& Behaviour, 17(3), 215231 .

Street, B. (2004). Academic literacies and the 'new orders': implications for research and practice in student writing in higher education. Learning and Teaching in the Social Sciences, 1(1), 9-20.

Sutherland-Smith, W. (2005). Pandora's box: academic perceptions of student plagiarism in writing. Journal of English for Academic Purposes, 4, 83-95.

Turner, S. P., \& Beemsterboer, P. L. (2003). Enhancing academic integrity: Formulating effective honor codes. Journal of Dental Education, 67(10), 1122-1129.

Vaismoradi, M., Turunen, H., \& Bondas, T. (2013). Content analysis and thematic analysis: Implications for conducting a qualitative descriptive study. Nursing \& Health Sciences, 15(3), 398-405.

Valentine, K. (2006). Plagiarism as literacy practice: Recognizing and rethinking ethical binaries. College Composition and Communication, 58(1), 89-109.

Vehviläinen, S. \& Löfström, E. (2016). 'I wish I had a crystal ball': discourses and potentials fordeveloping academic supervising. Studies in higher education, 41(3), 505-524. doi:10.1080/03075079.2014.942272.

Walker, J. (2010). Measuring plagiarism: researching what students do, not what they say they do. Studies in Higher Education, 35(1), 41-59.

Wheeler, G. (2009). Plagiarism in the Japanese Universities: Truly a cultural matter? Journal of Second Language Writing, 18, 17-29. 